\title{
SINTER RECRYSTALIZATION AND PROPERTIES EVALUATION OF GLASS-CERAMIC FROM WASTE GLASS BOTTLE AND MAGNESITE FOR EXTENDED APPLICATION
}

\author{
A. I. Gebi, S.A. Yaro, M. Abdulwahab*, M.R. Dodo \\ Department of Metallurgical and Materials Engineering, \\ AhmaduBelloUniversity, Zaria, Nigeria
}

Received 22.09.2016

Accepted 27.12.2016

\begin{abstract}
In a bid to address environmental challenges associated with the management of waste Coca- Cola glass bottle, this study set out to develop glass ceramic materials using waste coca cola glass bottles. Magnesite from Sakatsimta in Adamawa state and reagent grade chrome (coloring agent) were used to modify the composition of the Coca- Cola glass bottle. X-ray fluorescence (XRF), X-ray diffraction (XRD) and thermo gravimetric analysis (TGA) were used to characterize raw materials. Four batches: GC$1=$ Coca- Cola glass frit $+1 \% \quad \mathrm{Cr}_{2} \mathrm{O}_{3}, \mathrm{GC}-2=97 \%$ Coca- Cola glass frit $2 \%$ magnesite $+1 \% \mathrm{Cr}_{2} \mathrm{O}_{3}, \mathrm{GC}-3=95 \%$ Coca- Cola glass frit+ $4 \%$ magnesite $+1 \% \mathrm{Cr} 2 \mathrm{O} 3$, GC$4=93 \%$ Coca- Cola glass frit $+6 \%$ magnesite $+1 \% \mathrm{Cr}_{2} \mathrm{O}_{3}$ were formulated and prepared. Thermal gradient analysis (TGA) results were used as a guide in selection of three temperatures $\left(700,750\right.$ and $\left.800^{\circ} \mathrm{C}\right)$; three particle sizes $-106+75,-75+53,-53 \mu \mathrm{m}$ and 2 $\mathrm{h}$ sintering time were also used; the sinter crystallization route of glass ceramic production was adopted. The samples were characterized by X-ray diffraction (XRD) analysis. The resulting glass ceramic materials composed mainly of wollastonite, diopside and anorthite phases depend on composition as indicated by XRD.

Keywords: sintering temperature, crystal formation, glass ceramic, residual glassy phase
\end{abstract}

\section{Introduction}

The chronology of the human race from inception has been predicated on one material or the other in the form of tools or simple machine for usage [1]. Modern science and technology constantly require new materials with special properties to achieve breathtaking innovations. This development centers on the improvement of scientific and technological fabrication and working procedures by rendering them faster, economically more viable and better in quality. At the same time, new materials are introduced to improve general quality of life. Among the entire new materials, glass

\footnotetext{
* Corresponding author: M. Abdulwahab,mabdulwahab@abu.edu.ng
} 
ceramic materials play a very special role as they offer the possibility of combining the special properties of conventional sintered ceramics with the distinctive characteristic of glass [2].

Glass ceramics are normally produced from specially formulated compositions which usually contain a nucleating agent. They are melted and shaped into articles of desired geometry and then cooled to glass [3]. After that the glass articles are subjected to heat treatments to initiate the growth of crystals in situ. Commonly, such heat treatment process is carried out in two steps, at the temperature within or slightly above the transformation range, to develop nuclei in the glass, and then followed by another higher temperature treatment to enhance the growth of crystals on the formed nuclei [4].

The composition of the crystalline phases and the crystallite sizes define the properties of the final material. Therefore, the major components and the composition of the parent glass are selected to ensure precipitation of crystals that provide desired properties on a glass-ceramic [2]. In the case of internally nucleated glass-ceramics, the use of high specific surface glass-powders will act as uniformly scattered nuclei and no addition of a special nucleating agent is required. Subsequently, densification of the glass-powder compact must take place prior to devitrification. This sequence of events starting near the end of the sintering stage comes before crystallization starts which allows dense materials to be obtained [5].

The Nigerian bottling company in its effort to address environmental and social challenges is working to reduce the environmental impacts of its packaging at every stage of its lifecycle. To achieve this, it has considered many factors such as the weight and volume of solid wastes generated, the energy consumed in manufacturing and delivering various types of packaging, etc. Polyethylene terephthalate (PET) was concluded to be the fastest growing packaging option in the industry. The preference for PET bottles leaves us with a number of waste glass bottles that have been produced over the years, thereby adding to the existing environmental challenges of waste management and control.

The aim of this research work is to develop and characterize a glass ceramic material by sinter crystallization of waste Coca Cola glass bottles and magnesite.

\section{Materials and Methods}

Materials used in this research work are: Coca-Cola glass bottle, magnesite from Sakasimta Adamawa State, distilled water, chrome. The following equipment and methods were used: weighing balance, ball mill, measuring cylinder, spring balance, hydraulic press, crucible furnace, universal materials testing machine, thermo gravimetric analysis (TGA), X-ray fluorescence (XRF), X-ray diffraction (XRD), scanning electron microscopy (SEM) and Vickers micro hardness testing. The physical properties investigated were: density, porosity and mechanical properties including flexural strength (ASTM- C348) and hardness (ASTM-C1327).

\section{Batch Formulation and Preparation}

In the light of the chemical analysis of Coca-Cola bottle, it was decided to modify the composition in order to make it more suitable for obtaining glass ceramic materials. Coca-Cola glass bottle, magnesite and chrome (coloring agent) were used as starting materials in batch preparations of the glass ceramics. Four batches graded as: GC-1, GC-2, GC-3 and GC-4 were used for the study. The corresponding nominal and 
calculated compositions (from XRF results) of the batches are given in Table 1 . Three fractions of sizes: $-106+75,-75+53$ and $-53 \mu \mathrm{m}$ were used. Similarly, sintering was carried out for $2 \mathrm{~h}$. The temperatures at which the sintering was conducted were: 700 , 750 and $800^{\circ} \mathrm{C}$. Samples were designated as: $\mathrm{G}_{\mathrm{MPT}}$ where $\mathrm{M}=0,1,2,3$ for $0,2,4,6 \%$ magnesite, respectively. $\mathrm{P}=1,2,3$ for $-106+75,-75+53,-53 \mu \mathrm{m}$ were size fractions, respectively, whereas $\mathrm{T}=1,2,3$ for 700,750 and $800^{\circ} \mathrm{C}$ were operating temperatures. The magnesite was calcined at $400^{\circ} \mathrm{C}$ for $2 \mathrm{~h}$ and the components of each batch were accurately weighed and properly mixed. 5M polyvinyl alcohol (PVA) was used as binder and samples were prepared in the ratio of $98.5 \%$ material and $1.5 \%$ binder. 324 rectangular bar $(61 \mathrm{~mm} \times 16 \mathrm{~mm} \times 5 \mathrm{~mm})$ samples, 9 samples for each set of conditions of $\mathrm{M}, \mathrm{P}$ and $\mathrm{T}$ were prepared based on conventional powder methods for producing ceramics (i.e. milling, weighing and mixing, granulating, weighing, pressing and sintering).

Table 1: raw material composition of batches

\begin{tabular}{lc}
\hline Batch & Composition \\
\hline GC-1 & $99 \%$ Coca-Cola glass frit $+1 \% \mathrm{Cr}_{2} \mathrm{O}_{3}$ \\
GC-2 & $97 \%$ Coca-Cola glass frit $+2 \%$ magnesite $+1 \% \mathrm{Cr}_{2} \mathrm{O}_{3}$ \\
GC-3 & $95 \%$ Coca-Cola glass frit $+4 \%$ magnesite $+1 \% \mathrm{Cr}_{2} \mathrm{O}_{3}$ \\
GC-4 & $93 \%$ Coca-Cola glass frit $+6 \%$ magnesite $+1 \% \mathrm{Cr}_{2} \mathrm{O}_{3}$ \\
\hline
\end{tabular}

\section{Results and Discussion}

The results obtained from the experiments are presented in Table 2 and Figures $1-20$.

$X$-ray Fluorescence $(X R F)$ and $X$-ray Diffraction $(X R D)$ analyses

Table 2: Chemical composition of Coca-Cola glass bottle and magnesite

\begin{tabular}{lcc}
\hline Oxides & Coca-Cola bottle (\%) & Magnesite (\%) \\
\hline $\mathrm{SiO}_{2}$ & 68.07 & 8.12 \\
$\mathrm{Na}_{2} \mathrm{O}$ & 13.15 & 0.10 \\
$\mathrm{Al}_{2} \mathrm{O}_{3}$ & 1.99 & 1.10 \\
$\mathrm{MgO}$ & 0.45 & 39.90 \\
$\mathrm{P}_{2} \mathrm{O}_{5}$ & 0.04 & 0.02 \\
$\mathrm{SO}_{3}$ & 0.41 & 0.03 \\
$\mathrm{CL}$ & 0.02 & - \\
$\mathrm{K} 2 \mathrm{O}$ & 0.78 & 0.28 \\
$\mathrm{CaO}$ & 14.04 & 3.45 \\
$\mathrm{TiO}_{2}$ & 0.13 & 0.10 \\
$\mathrm{Cr}_{2} \mathrm{O}_{3}$ & 0.02 & 0.002 \\
$\mathrm{MnO}$ & 0.01 & - \\
$\mathrm{Fe}_{2} \mathrm{O}_{3}$ & 0.73 & 0.74 \\
$\mathrm{ZnO}_{\mathrm{Rb}} \mathrm{O}$ & 0.01 & - \\
$\mathrm{SrO}_{2}$ & 0.005 & - \\
$\mathrm{ZrO}_{2}$ & 0.09 & 0.015 \\
$\mathrm{PbO}_{\mathrm{Mn}} \mathrm{O}_{5}$ & 0.03 & - \\
$\mathrm{LOI}$ & 0.014 & - \\
\hline & - & 0.03 \\
& - & 46.113 \\
\hline
\end{tabular}


Table 2 depicts result of XRF analysis of Coca-Cola glass frits and magnesite. The result revealed that it belongs to $\mathrm{SiO}_{2}-\mathrm{CaO}-\mathrm{Na}_{2} \mathrm{O}$ base glass composition system. Magnesite contained 39.90\% MgO alongside other oxides. On the other hand, Figure 1 shows result of XRD analysis of magnesite. According to the XRD result, magnesite contains $96.15 \%$ magnesite, $2.02 \%$ quartz and $1.83 \%$ dolomite.

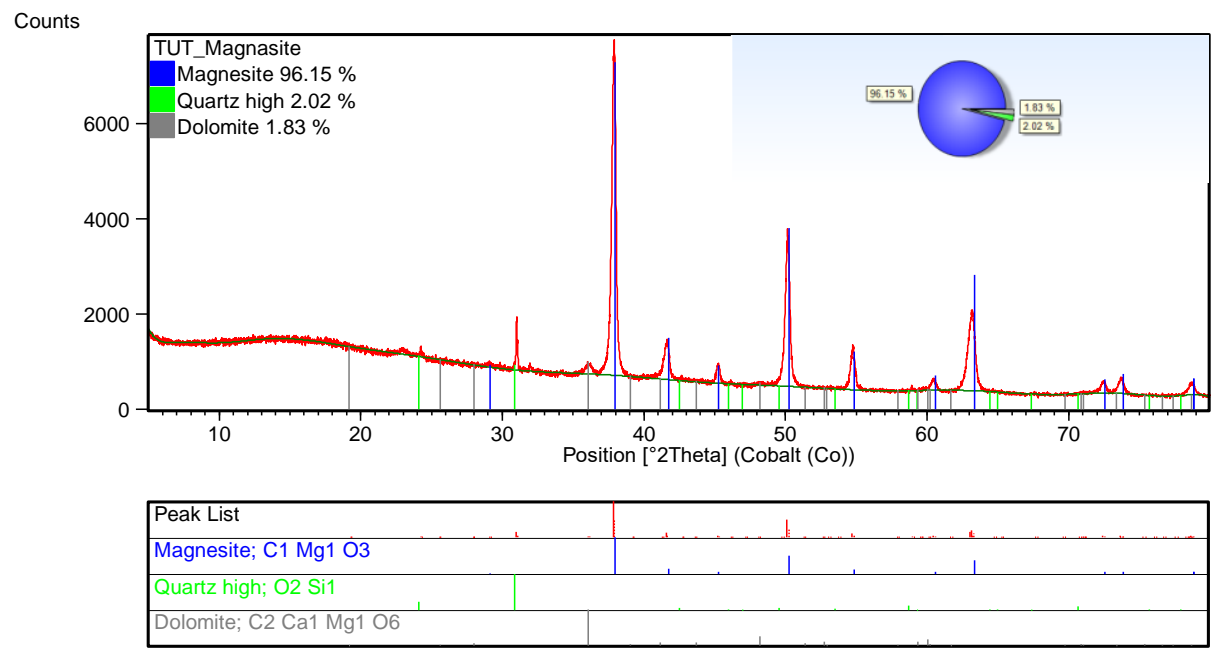

Fig. 1. XRD pattern of magnesite used

XRD analyses of the samples GC-1, GC-2, GC-3 and GC-4 are shown in Figures 2 and 3. After sintering the appearance of wollastonite $\left(\mathrm{CaSiO}_{3}\right)$, diopside $\left(\mathrm{Ca}, \mathrm{Mg}\left(\mathrm{SiO}_{3}\right)_{2}\right)$ and weak anorthite $\left(\mathrm{CaAl}_{2} \mathrm{Si}_{2} \mathrm{O}_{8}\right)$ peaks can be seen. XRD results of glass heat-treated ceramic compacts suggest consecutive transformation of the parent glass into crystalline phases. Figure 4 shows the evolution of the GC-1 sample. The degree of crystallinity of formed phases and the composition of the residual glass was changed with temperature evolution. The X-ray pattern of the GC-1 sample obtained at $700^{\circ} \mathrm{C}$ is still basically composed of an amorphous glassy phase and a few intensity peaks of wollastonite $\left(\mathrm{CaSiO}_{3}\right)$ are observed. Further temperature increase to $800^{\circ} \mathrm{C}$ enhances the intensity of the wollastonite peaks. The X-ray pattern of the GC-2 sample obtained at $700^{\circ} \mathrm{C}$ is still basically composed of an amorphous glassy phase and a few intensity peaks of wollastonite $\left(\mathrm{CaSiO}_{3}\right)$ were observed as well as weakly defined new phases of monoclinic diopside $\left(\mathrm{CaMgSi}_{2} \mathrm{O}_{6}\right)$ and anorthite. It seems that diopside and anorthite peaks were more pronounced in the sample with higher magnesite content (Figure 3). Moreover, X-ray diffraction showed that diopside, weak anorthite and wollastonite were the main crystalline phases developed in the investigated glasses. Their portion depended on base composition. In the sample GC-1, wollastonite $\left(\mathrm{CaSiO}_{3}\right)$ phase was crystallized. In the samples GC-2 to GC-4, the diopside and weak anorthite were also developed. Increase in the intensity of their lines was noticed. The increased intensities of diopside diffraction lines and their slight shift to higher $2 \theta$ values indicated a solid solution character. 


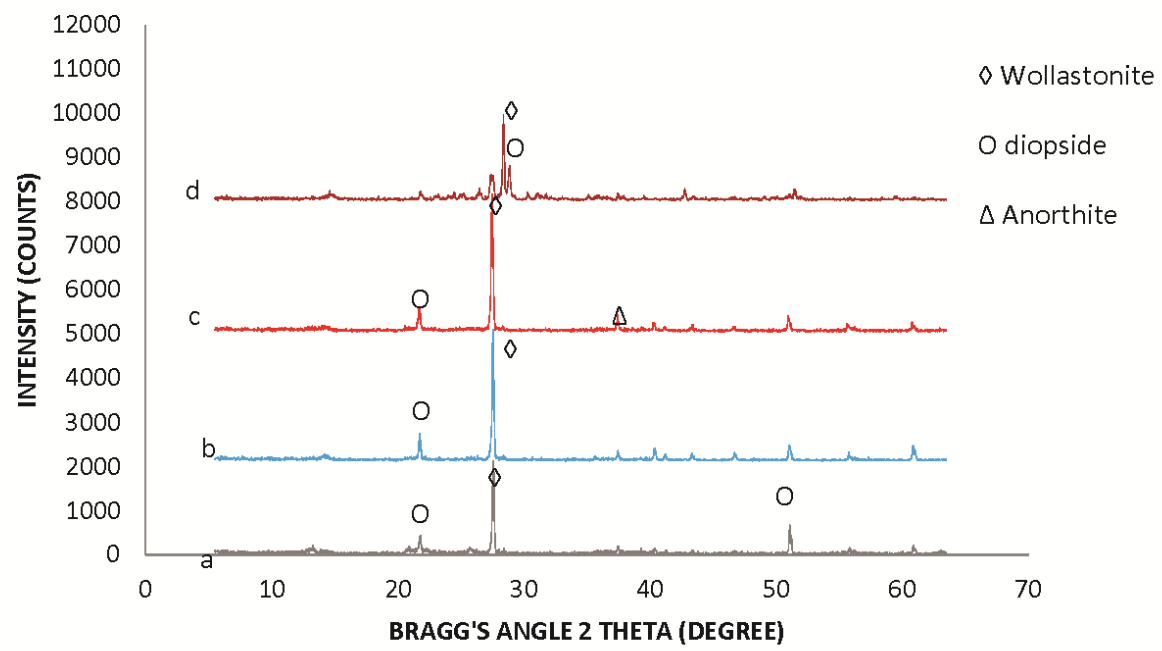

Fig. 2. X-ray diffraction patterns for: a) $\left.G C-1\left(-53 \mu \mathrm{m}, 700^{\circ} \mathrm{C}\right), \mathrm{b}\right) \mathrm{GC}-1\left(-53 \mu \mathrm{m}, 800^{\circ} \mathrm{C}\right)$, c) $G C-2\left(-75+53 \mu \mathrm{m}, 700^{\circ} \mathrm{C}\right)$, d) $G C-2\left(-75+53 \mu \mathrm{m}, 700^{\circ} \mathrm{C}\right)$

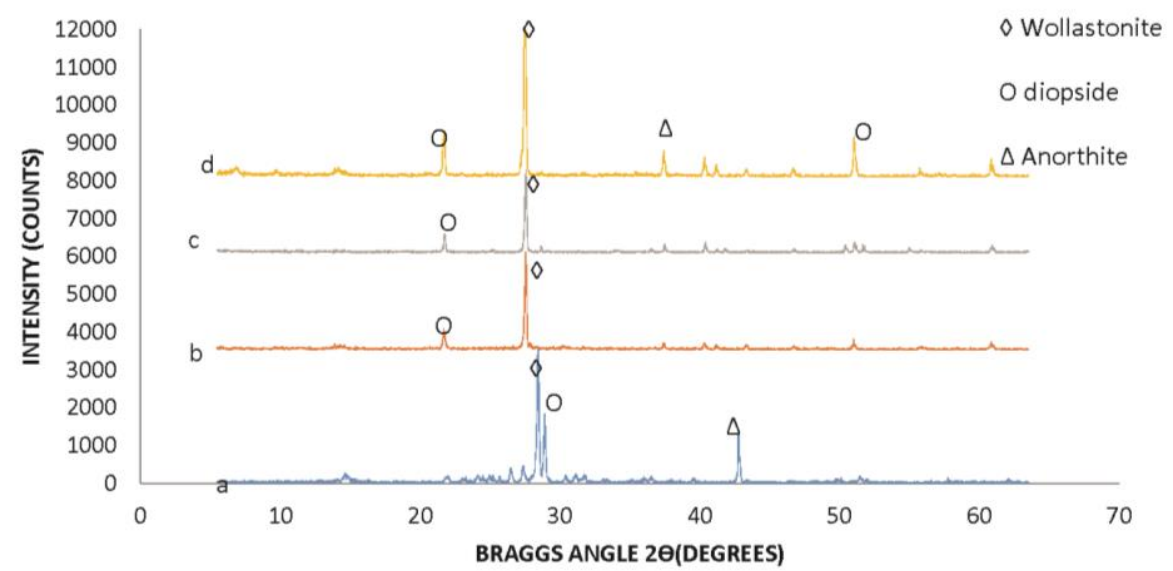

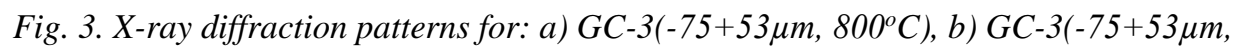
$\left.750^{\circ} \mathrm{C}\right)$, c) $\mathrm{GC}-4\left(-75+53 \mu \mathrm{m}, 800^{\circ} \mathrm{C}\right)$, d) $\mathrm{GC}-4\left(-53 \mu \mathrm{m}, 750^{\circ} \mathrm{C}\right)$

The sequence of events during glass powder heat-treatment was as follows: (i) near the glass transition temperature $(\mathrm{Tg})$, the parent glass fine particles acted as uniformly scattered nuclei; chrome also precipitated from the glass and formed nucleation points for the crystallization of wollastonite and diopside, and consequently induced the crystallization of the glasses. (ii) further heating led to an increase in the viscosity of the batch and promoted densification by viscous coalescence; (iii) around 
$700^{\circ} \mathrm{C}$ crystallization started, resulting in the precipitation of wollastonite. Increasing temperature improved the degree of crystallinity and densification, and a fully dense glass-ceramic material composed of wollastonite, weak anorthite, and diopside crystals plus some residual glassy phase was formed. Furthermore, it is believed that during the sintering process chrome precipitated from the glass and formed nucleation cites for the crystallization of wollastonite and diopside, and consequently induced the crystallization of the glasses as affirmed by Khater et al. [3].

\section{Thermo Gravimetric Analysis (TGA)}

The TGA analysis is a useful method to determine the optimal stabilization temperature [6]. TGA of Coca-Cola glass bottle was done in the temperature range of $30-1000^{\circ} \mathrm{C}$ in order to find the crystallization temperature of different crystalline phases as shown in Figure 4. The total weight loss was observed after heating up to $750^{\circ} \mathrm{C}$. Since the specimen was not fully dried, some physically bound water was present at the surface and in micro pores, which caused a subsequent loss of mass at the lowest temperature range, i.e., $50-400^{\circ} \mathrm{C}$. This process is endothermic and is connected with decomposition of water vapors. Between $400-700^{\circ} \mathrm{C}$ the weight loss was slow and steady, which probably is connected to glass transition/transformation, and from 700$750^{\circ} \mathrm{C}$ the weight loss was constant due to the onset of sintering/nucleation. The nucleation temperature of the crystal is a strong function of the heating rate as found by Durrani et al. [6]. It was observed that increasing the heating rate shifted the nucleation temperature to a higher value. 


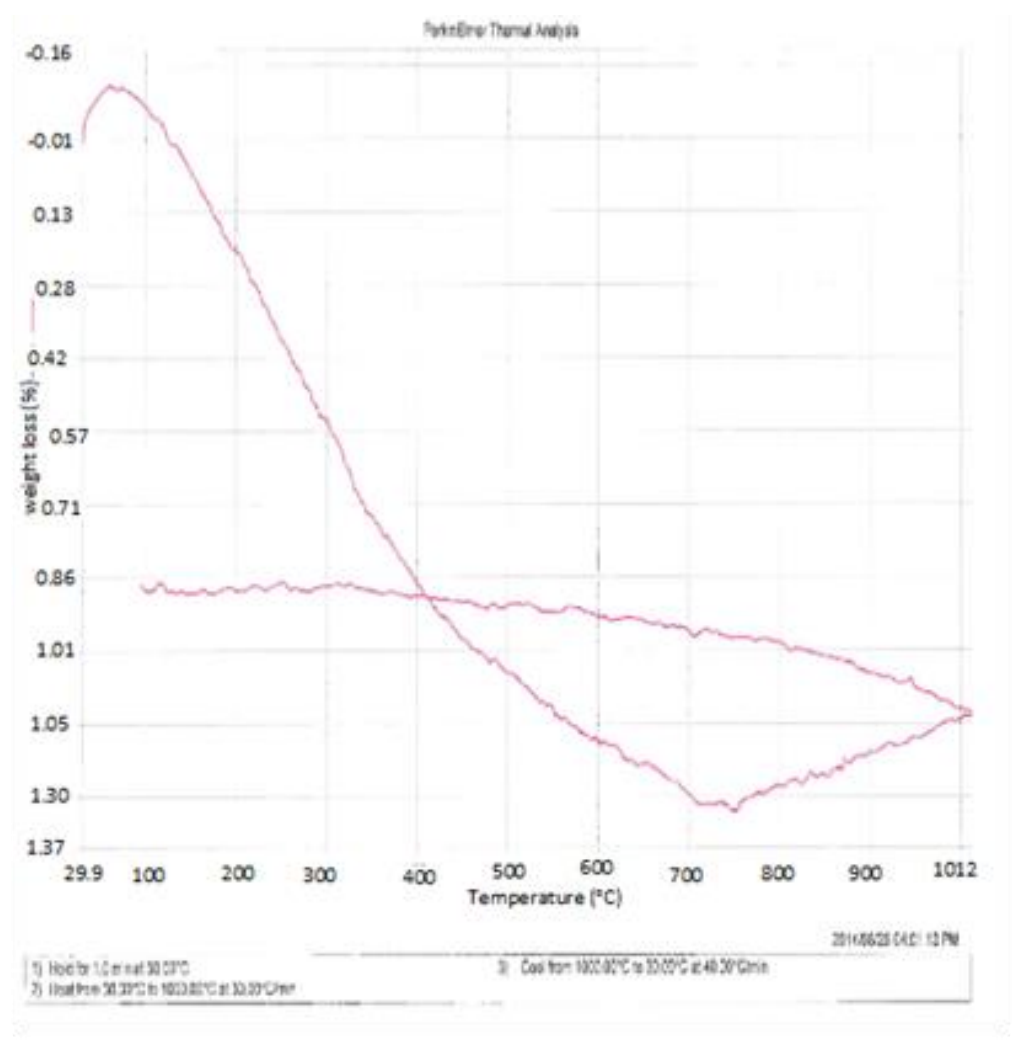

Fig. 4. TGA curve of the waste glass sample

Scanning Electron Microscopy examination of the glass ceramic materials

Figure 5 to 12 show the representative microstructure and morphology from GC1 to GC-4 samples. Two different morphologies: fine fibrous crystals assigned to wollastonite and diopside and tiny spherulites assigned to anorthite were observed. It was observed that for GC-1 sample (Figures 5 and 6) wollastonite is the main phase. However, as the percentage of magnesite increased fibrous growth of tiny diopside and appearance of tiny spherulites of anorthite was noticed, Figures 7-12. 

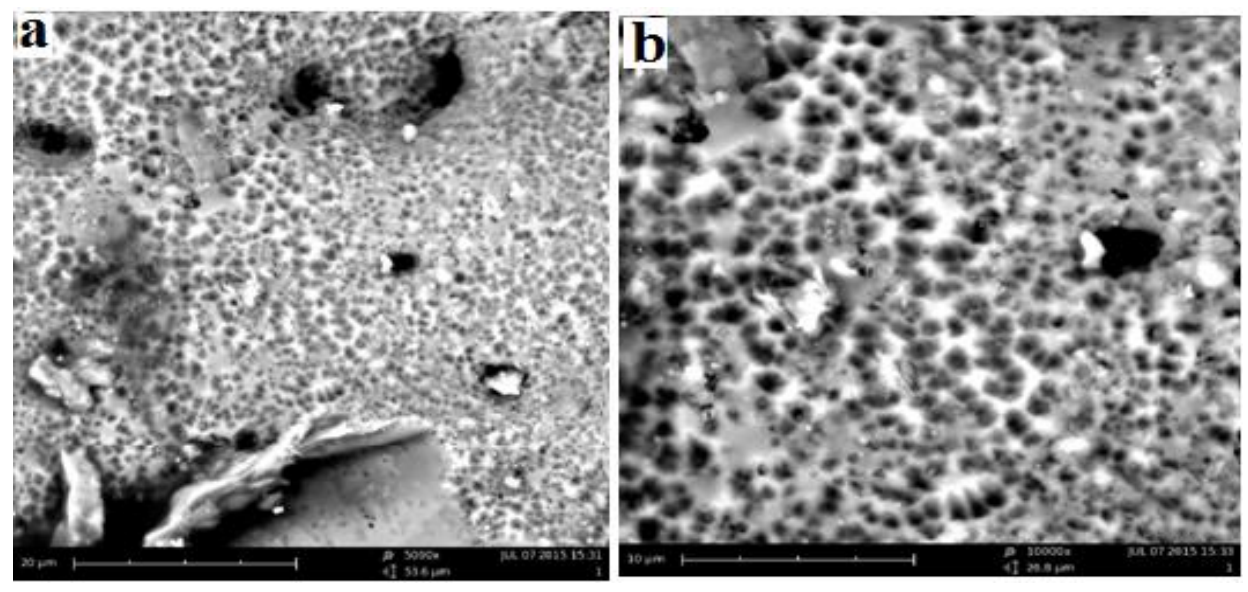

Fig. 5. SEM image of $G C-1\left(-53 \mu \mathrm{m}, 700^{\circ} \mathrm{C}\right)$, with fine texture of tiny wollastonite in residual glass matrix: a) $\times 5000$ b) $\times 10000$

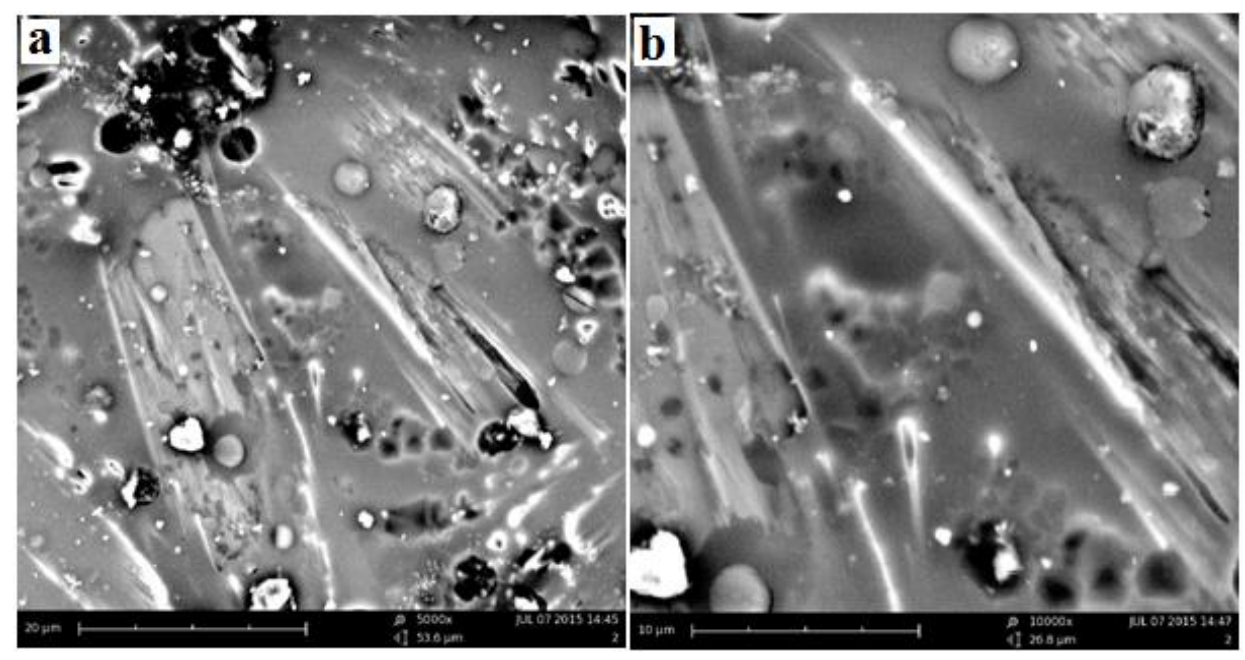

Fig. 6. SEM image of $G C-1\left(-53 \mu \mathrm{m}, 800^{\circ} \mathrm{C}\right)$ with fibrous growth of wollastonite in residual glass matrix: a) $\times 5000$ b) $\times 10000$ 

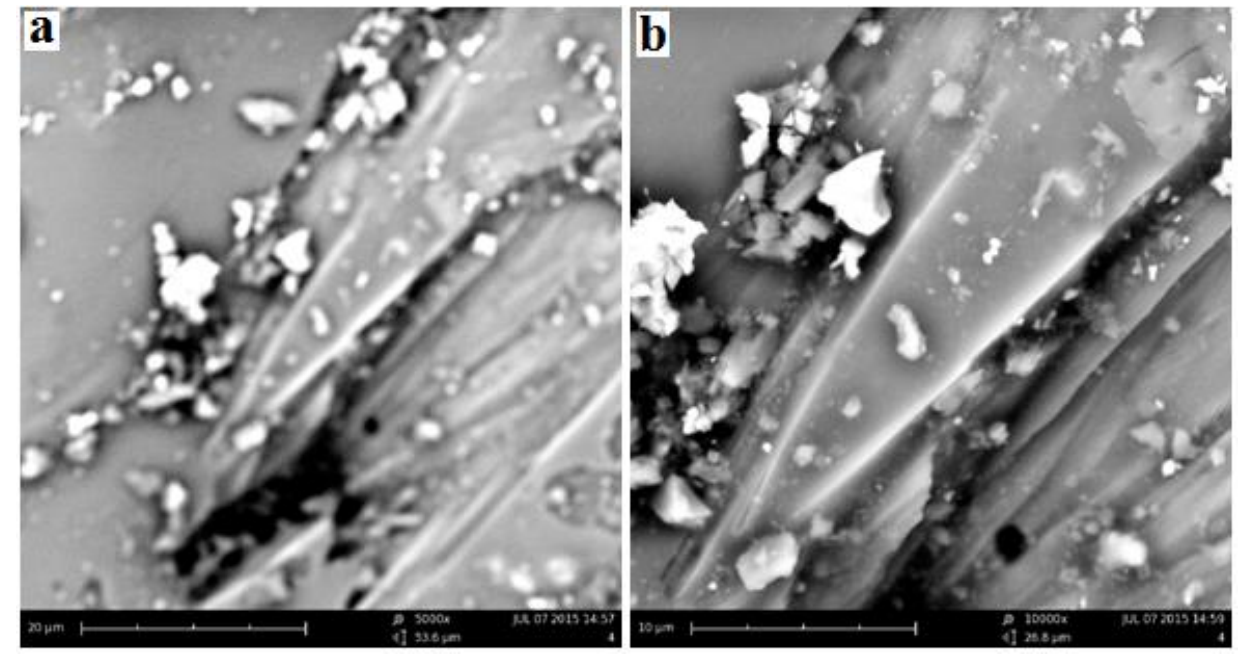

Fig. 7. SEM image of $G C-2\left(-75+53 \mu \mathrm{m}, 700^{\circ} \mathrm{C}\right)$ with fibrous growth of tiny diopside and wollastonite with appearance of tiny spherulites of anorthite. a) x5000 b) x10000

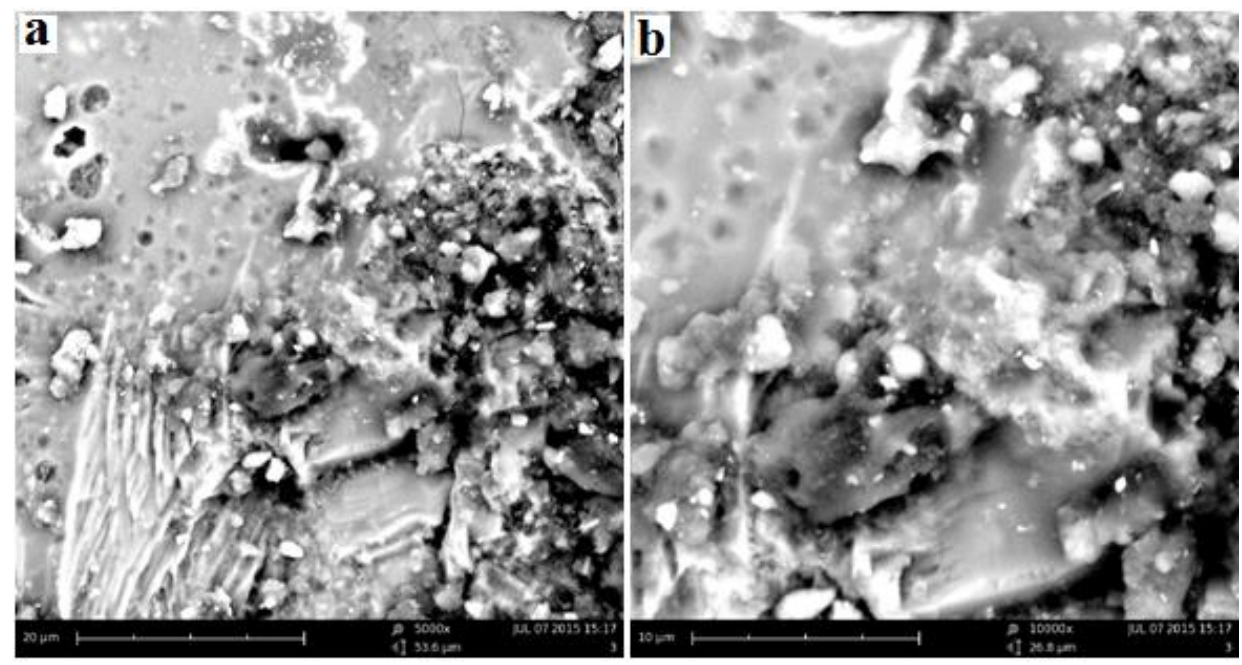

Fig. 8. SEM image of $G C-2\left(-75+53 \mu m, 800^{\circ} \mathrm{C}\right)$ showing fibrous growth of tiny diopside and wollastonite with more appearance of tiny spherulites of anorthite. a) x5000 b) $x 10000$ 

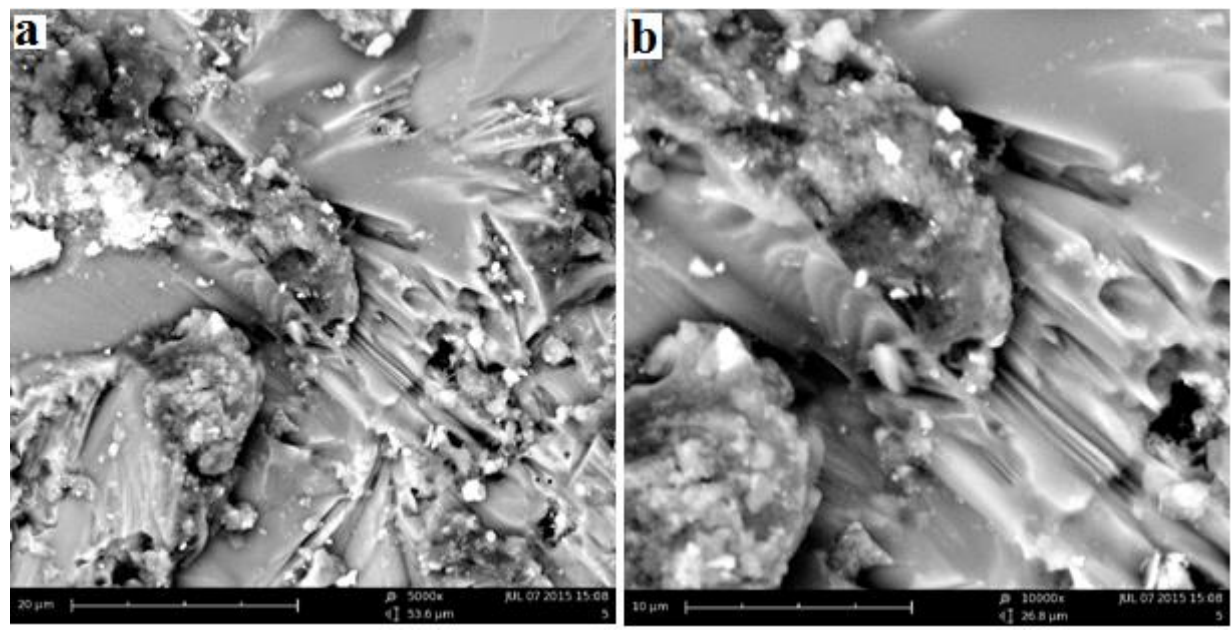

Fig. 9. SEM image of $\mathrm{GC}-3\left(-75+53 \mu \mathrm{m}, 800^{\circ} \mathrm{C}\right.$ showing fibrous growth of tiny diopside and wollastonite with appearance of tiny spherulites of anorthite). a) x5000 b) x10000

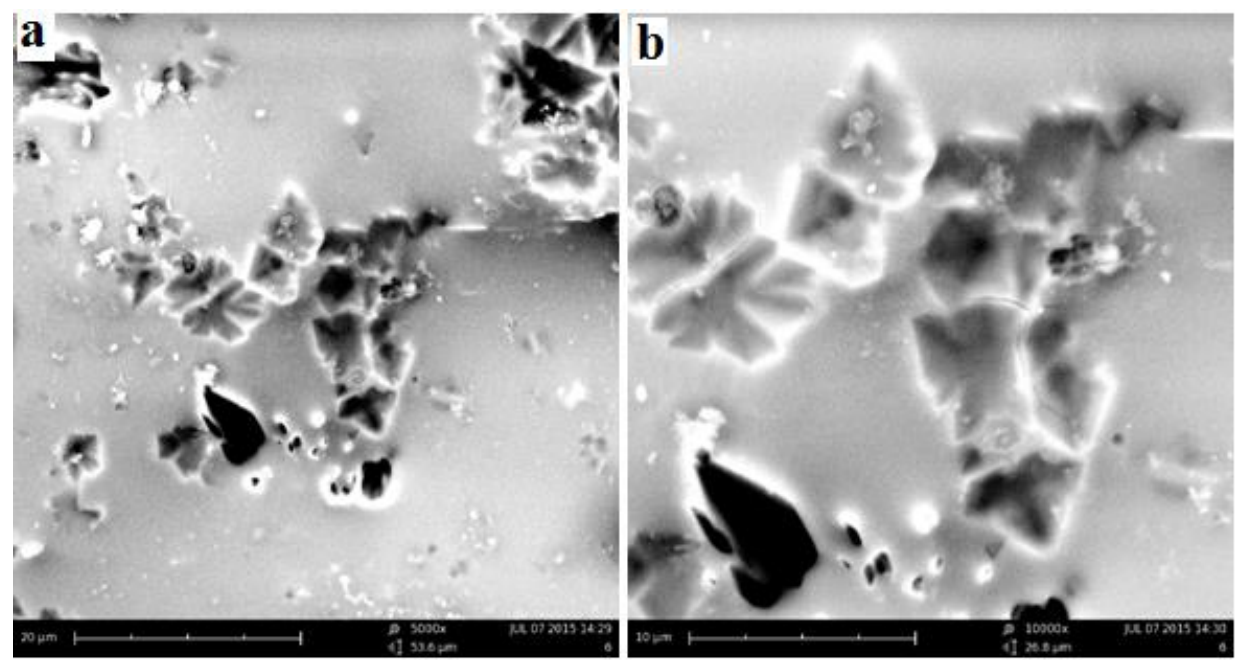

Fig. 10. SEM image of $G C-3\left(-75+53 \mu \mathrm{m}, 750^{\circ} \mathrm{C}\right)$ showing a glassy phase of diopside and wollastonite with appearance of tiny spherulites of anorthite with network of solid materials (white) and little evidence of porosity (black). a) x5000 b) x10000 

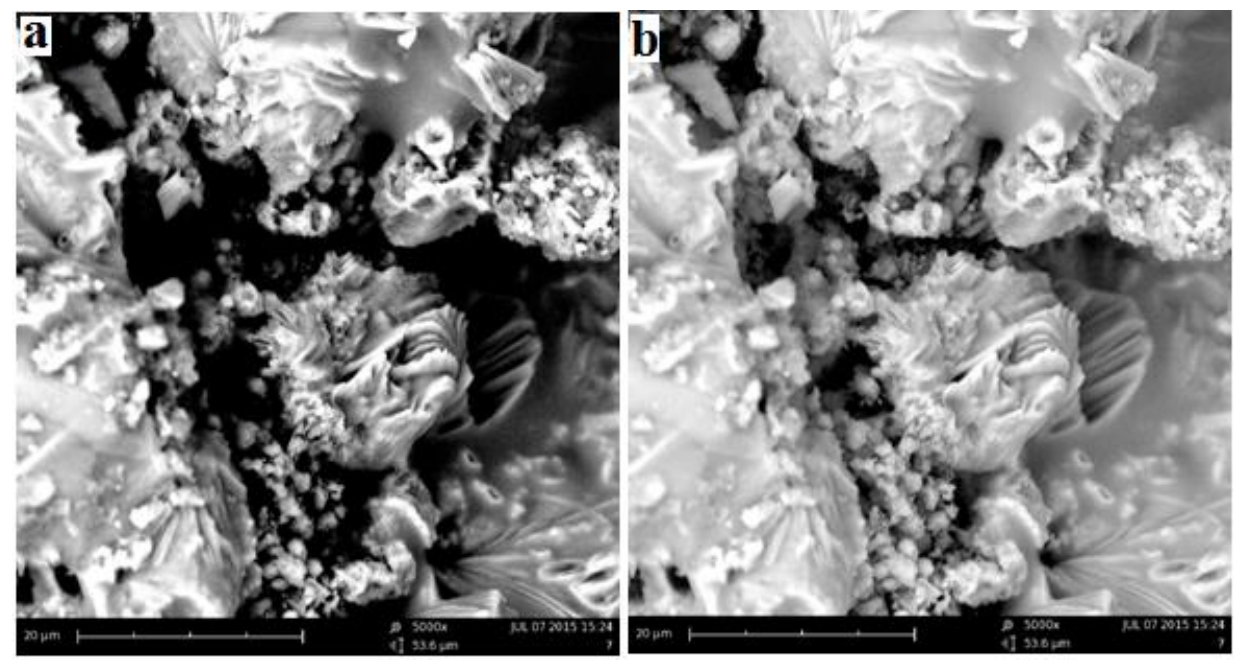

Fig. 11. SEM imageof $G C-4\left(-75+53 \mu \mathrm{m}, 800^{\circ} \mathrm{C}\right)$ showing more fibrous growth of diopside and wollastonite with more appearance spherulites of anorthite. a) x5000 b) $x 5000$

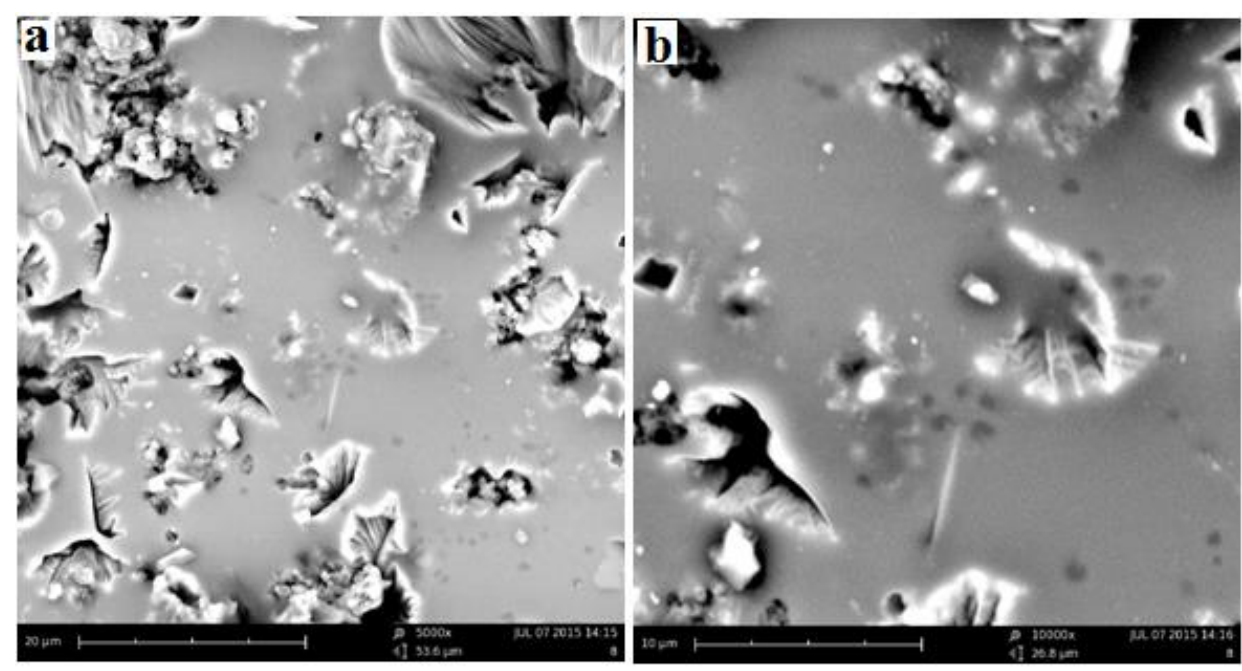

Fig. 12. SEM image of $G C-4\left(-53 \mu \mathrm{m}, 750^{\circ} \mathrm{C}\right)$ showing tiny diopside and wollastonite with appearance of tiny spherulites of anorthite and formation of a continous network of solid materials. a) x5000 b) x10000

The morphology of the crystal phases present in Figures 10 and 12 was quite different to the morphology observed for the other glass ceramics. The crystal phases seen in the matrix of amorphous glass were confirmed by the XRD which might have the presence of phosphorus, although no phosphorus containing crystal phase was identified in the glass ceramic. This led to the conclusion that phosphorus must have remained in the amorphous glass. Treatment of dispersed iron-bearing raw materials and 
modeling of the protection systems against air-pollution was present as $\mathrm{Ca}_{3}\left(\mathrm{PO}_{4}\right)_{2}$ in the glass as there is no other indication from the data presented here.

\section{Physical properties evaluation of the glass ceramic materials}

Figures 13 to 16 show variation of density with different conditions of particle size and temperature for GC-1 to GC-4. As expected, slightly higher density values were obtained for samples processed from finer particle sizes and higher temperatures. It was concluded that sinterability depended on the temperature at which the crystallization started. Therefore, with increase in the crystallization temperature, the glassy phase had enough time for viscous flow which led to complete densification, which agrees with Fernandes et al. [7]. It is also observed that the maximum density of samples was obtained at about $800{ }^{\circ} \mathrm{C}$. The measured density values for glass ceramics were increased with increasing magnesite content. This happened because the density depended on the type of phases as well as on the amount of each phase formed in the glass ceramics.

Porosity or void fraction is a measure of void spaces in a material, and is given as the ratio of the volume of all pores in a material to the total volume. Porosity is the result of gas entrapment in the solidifying glass ceramic materials. Figures 13 to 16 show variation of porosity with different conditions of particle size and temperature for GC-1 to GC-4. In most cases the porosity decreased with increasing temperature and decreasing particle size. This probably was because the use of fine particle sizes and high temperature promoted sintering consequently eliminating porosity.

As far as sintering is concerned, the experimental results showed that densification of sample compacts started at low temperatures $\left(700{ }^{\circ} \mathrm{C}\right)$, advanced at higher temperatures, likely by viscous flow sintering, and was almost completed at 800 ${ }^{\circ} \mathrm{C}$. On the other hand, crystallization started at temperatures below $700{ }^{\circ} \mathrm{C}$ and the crystallinity increases at higher temperatures, resulting in fully dense glass ceramic materials. Mirhadi and Mehdikhani, [8] proposed that the crystallization of diopside may cause formation of additional porosity since there is a significant difference between the density of diopisde in glassy $\left(2.75 \mathrm{~g} / \mathrm{cm}^{3}\right)$ and crystal state $\left(3.27 \mathrm{~g} / \mathrm{cm}^{3}\right)$. The difference of density is negligible: in the case of wollastonite $\left(2.87 \mathrm{~g} / \mathrm{cm}^{3}\right.$ and 2.92 $\mathrm{g} / \mathrm{cm}^{3}$ for the glass and the crystals, respectively). Furthermore, SEM micrographs of samples sintered at $800{ }^{\circ} \mathrm{C}$ showed that the samples are without surface porosity. This means that the increase of the viscous flow at higher temperatures $\left(800^{\circ} \mathrm{C}\right)$ was enough to eliminate the porosity that formed due to the crystallization of diopside. 


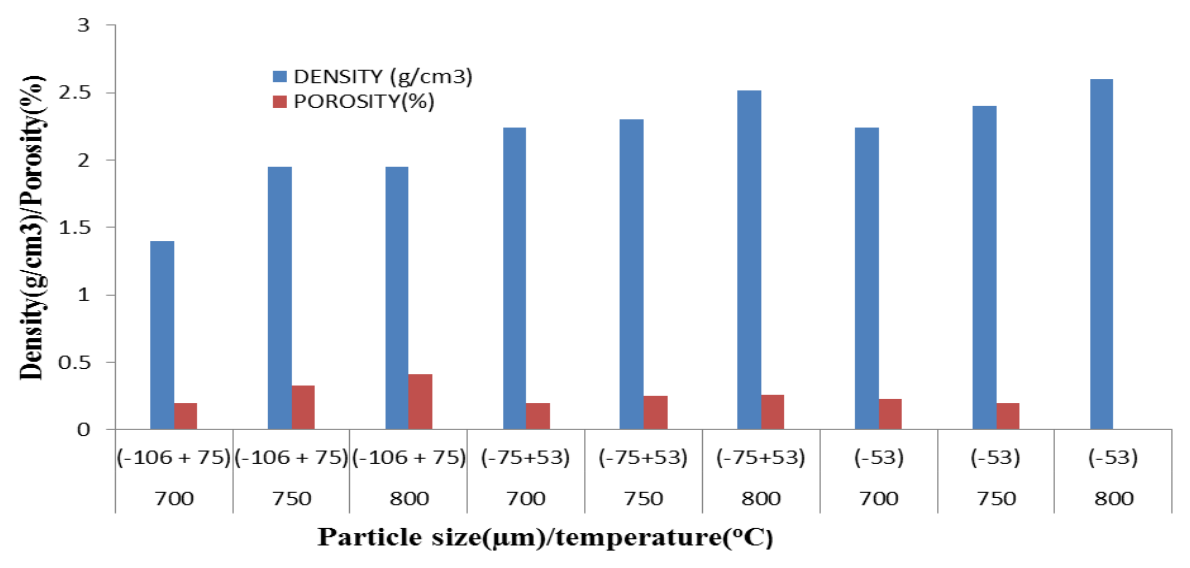

Fig. 13. Variation of density and porosity with different conditions of particle size and temperature of GC-1 samples.

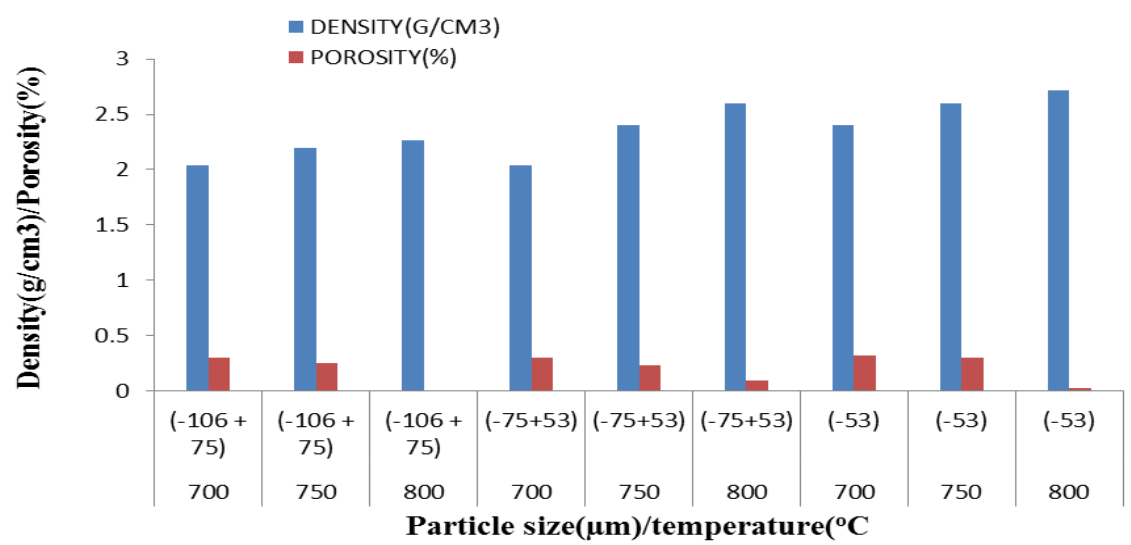

Fig. 14. Variation of density and porosity with different conditions of particle size and temperature for $G C-2$ samples. 


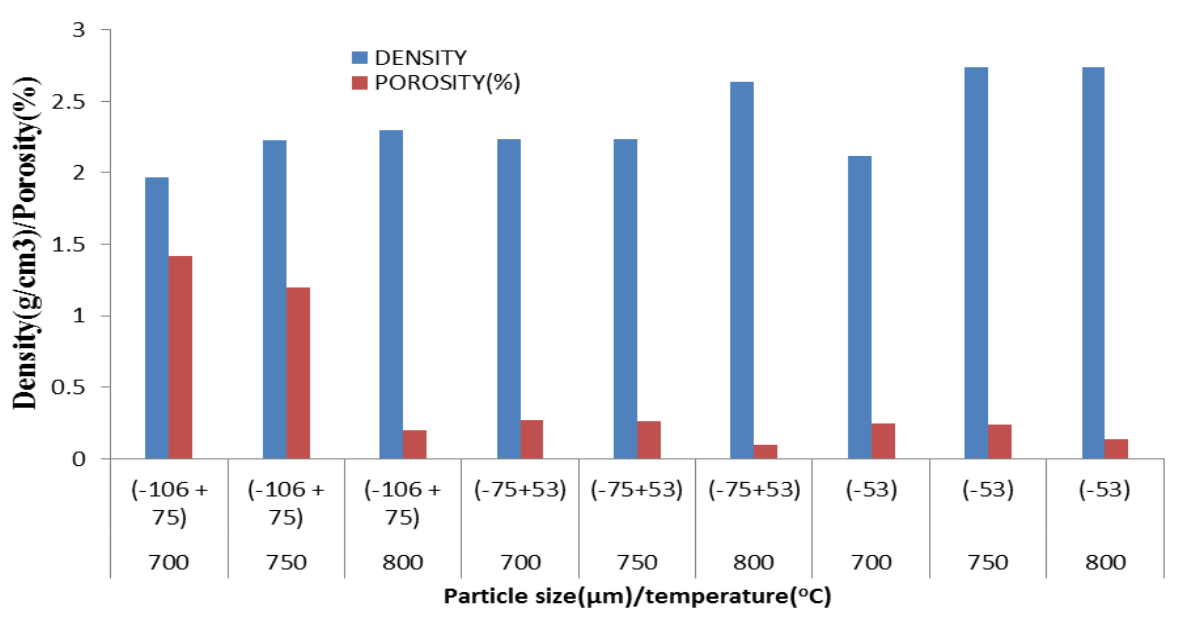

Fig. 15. Variation of density and porosity with different conditions of particle size and temperature for GC-3 samples.

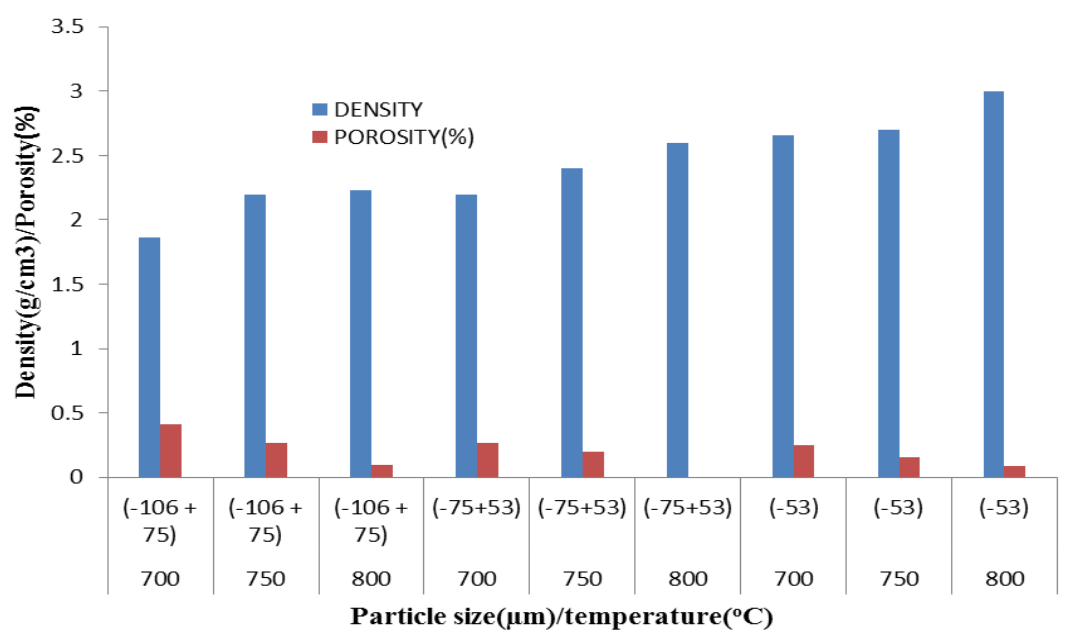

Fig. 16. Variation of density and porosity with different conditions of particle size and temperature for GC-4 samples.

Flexural strength and hardness behavior of the glass ceramic

Figures 17-20 show variation of flexural strength with different conditions of particle size and temperature for GC-1 to GC-4. The bending strength of the samples increased continuously up to the optimum sintering temperature, i.e. $800{ }^{\circ} \mathrm{C}$. Perhaps the lower densities of the samples were responsible for the lower bending strength. The bending strength of the samples increased with increasing magnesite content, this is because compared with wollastonite, diopside belongs to monoclinic system and has 
better mechanical properties and chemical stability. Both phases are inosilicates, which are well known for high strength and fracture toughness. This is due to the unidirectional backbone of tetrahedral silica linkage which often manifests itself as elongated acicular or rod like crystals providing reinforcement to the glass ceramic. Thus, Khater [4] proposed that diopside is a preferable crystalline phase since it results in stronger materials than glass ceramics based on wollastonite. Presented SEM images confirmed the crystalline nature of the samples and also interlocking fibrous dendritic sheaves and spherulites which help to enhance fracture toughness as affirmed by Hölland and Beall [2].

Figures 17-20, show variation of hardness with different conditions of particle size and temperature for GC-1 to GC-4. Vickers hardness numbers increased as the diopside-anorthite eutectic or magnesite contents increase. This indicates the high abrasion resistance of the materials which resulted to their suitability for many applications under aggressive conditions.

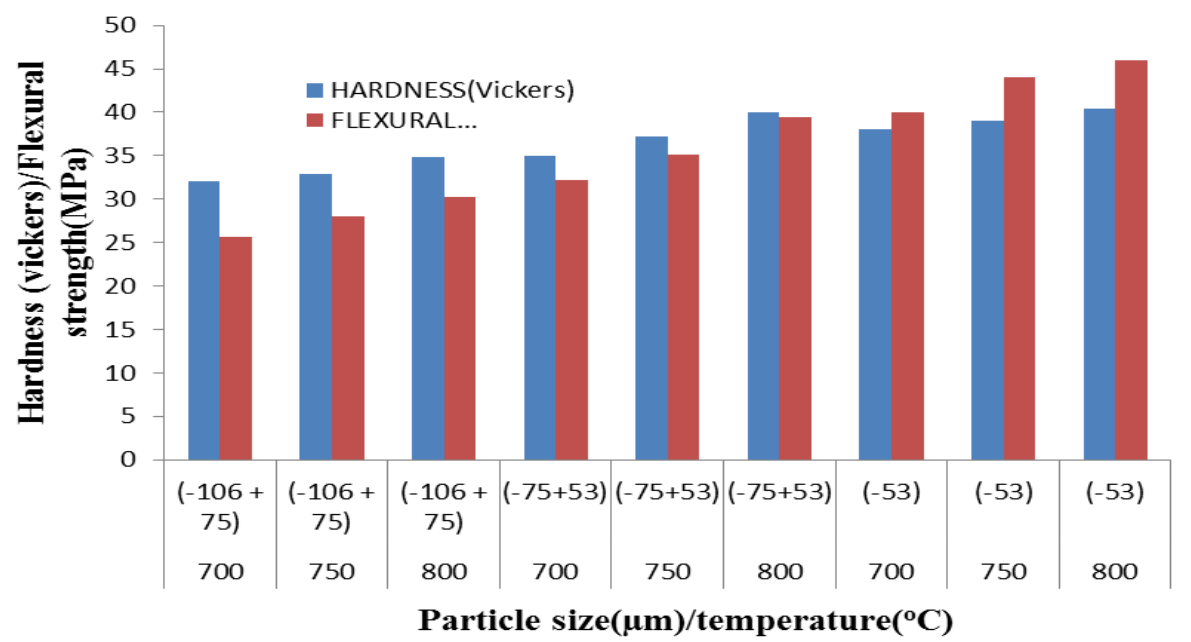

Fig. 17. Variation of hardness and flexural strength with different conditions of particle size and temperature for GC-1 samples. 


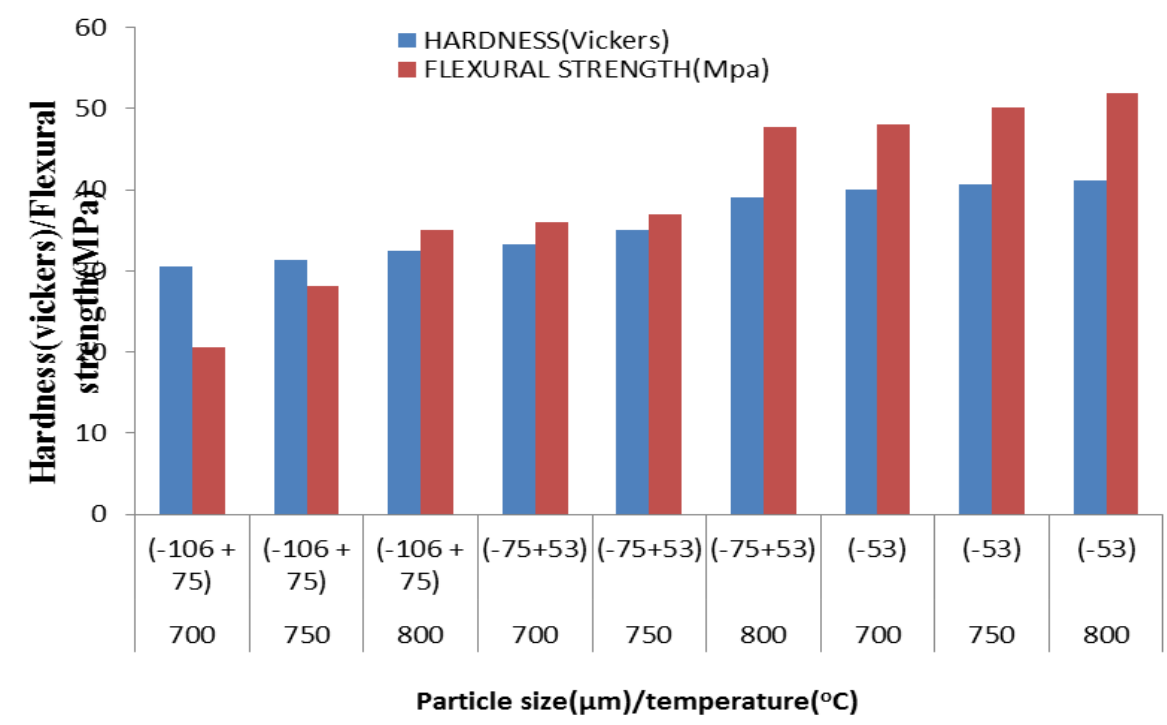

Fig.18. Variation of hardness and flexural strength with different conditions of particle size and temperature for GC-2samples.

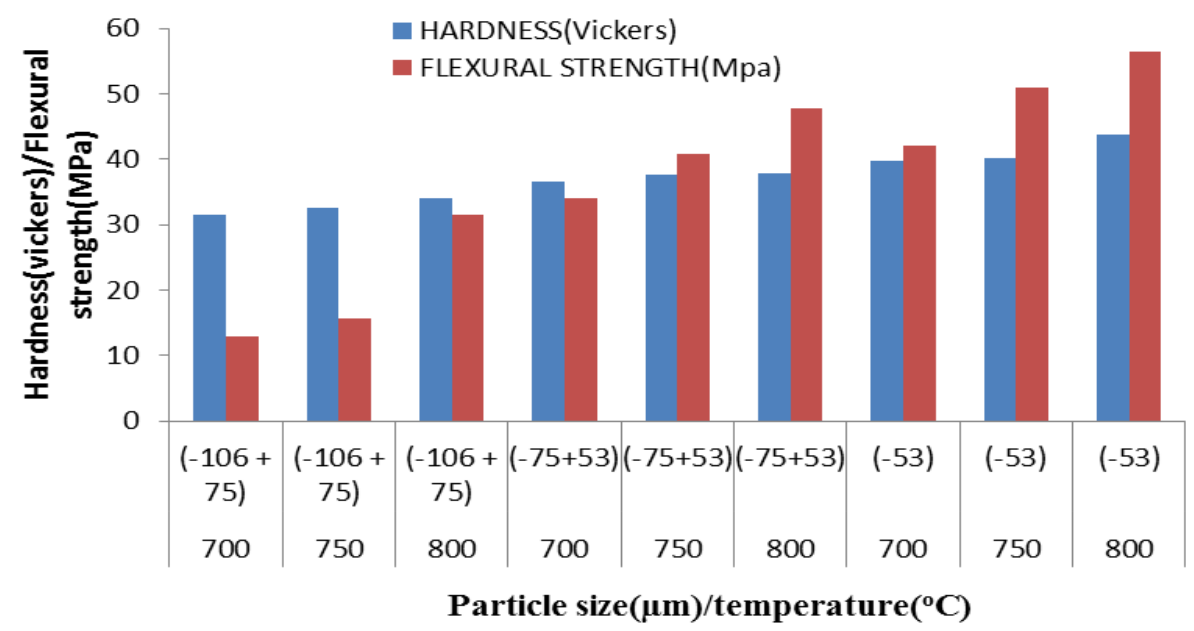

Fig. 19. Variation of hardness and flexural strength with different conditions of particle size and temperature for $G C$-3samples. 


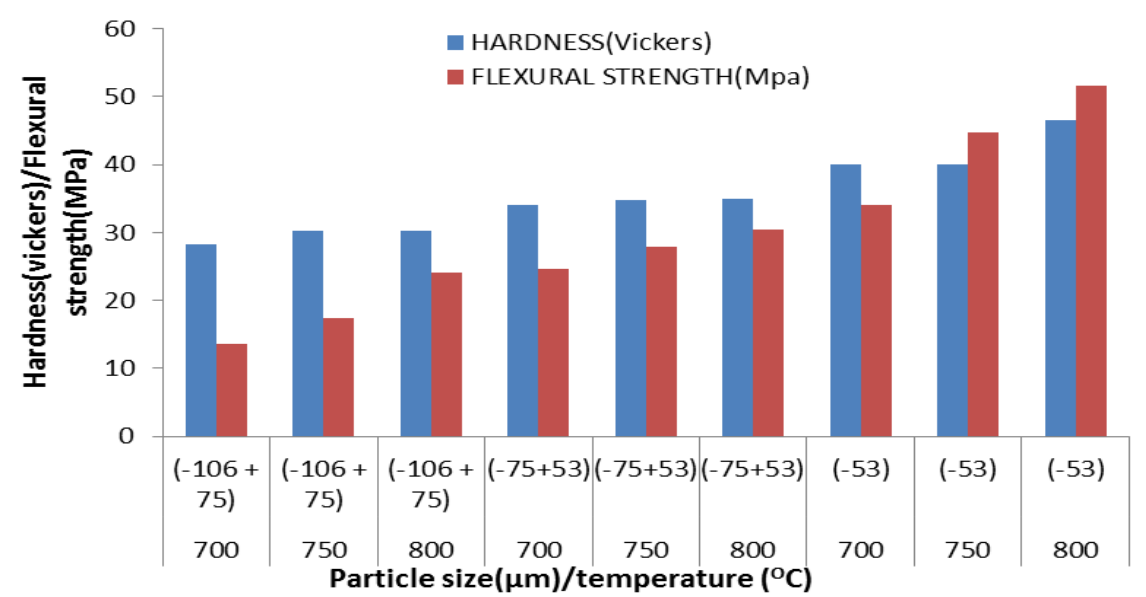

Fig. 20. Variation of hardness and flexural strength with different conditions of particle size $(\mu \mathrm{m})$ and temperature $\left({ }^{\circ} \mathrm{C}\right)$ for $\mathrm{GC}-4$ sample.

\section{Conclusions}

A glass ceramic using waste coca cola bottle and magnesite was successfully developed and characterized. Based on the results it can be concluded that Coca Cola glass bottle can be used to successfully produce glass ceramic materials with good properties. However, the resulting glass ceramic materials composed mainly of wollastonite, diopside and anorthite phases depend on composition. Additionally, modification of the glass bottle with magnesite enhanced the properties of the obtained glass ceramics due to the precipitation of more diopside and anorthite phases. Furthermore, the density of samples increased with increasing sintering temperature and decreasing particle size, while the porosity was minimal and it decreases with increasing sintering temperature and decreasing particle size. Thus, the obtained glass ceramic materials have appreciable hardness and flexural strength.

\section{Acknowledgements}

This material is based upon work conducted by Mrs Asma'u GEBI as part of her M.Sc. degree dissertation in Metallurgical and Materials Engineering. The equipment support at Department of Metallurgical and Materials Engineering Ahmadu Bello University, Zaria is highly appreciated.

\section{References}

[1] W.D.Callister, Materials science and engineering: an introduction, 8th edition, John Wiley \& Sons, E-Book: Wiley Desktop Edition, 2010.

[2] W. Hölland, and G.HBeall, Glass-ceramic Technology, The American Ceramic Society,Ohio, 2002.

[3] G.A.Khater, and M.H. Idris, Indust Ceram, 24 (2005) 43-49.

[4] G. A.Khater: Process Appl Ceram, 6 (2012), 109-116.

[5] C.Siligardi, M.C.D'Arrigo, C.Leonelli: J. of American Ceramic Soceity, Bull 79 (2000) 88-93. 
[6] S.K.Durrani, A. H Muhammad, S.Khalid, Z. H.Syed, A.Muhammad, and S.Ather, Synthesis and Sintering Studies of Magnesium Aluminum Silicate Glass Ceramic, Retrieved from Sintering of Ceramics http://www.intechopen.com/books/sinteringof-ceramics-new emergingtechniques/synthesis-and-sintering-studies-ofmagnesium-aluminum-silicate glass-ceramic 2012.

[7] H. R. Fernandes, D. U. Tulyaganov, A. Goel and J. Ferreira: J. of the European Ceramic Society 32(2) (2012), 291-298.

[8] B. Mirhadi and B. Mehdikhani, Process Appl Ceram, 6 (2012) 159-164.

[9] E.A.Ali, Development of low temperature glass ceramics from local raw materials,(Doctoral Dissertation ), Ahmadu Bello University, Zaria, Nigeria, 2008.

[10] D. I. Atkinson,P. W.McMillan: J Mat Sci, (1975) 443-450. 